\title{
REGENERAÇÃO NATURAL DE MYRTACEAE EM UMA UNIDADE DE CONSERVAÇÃO URBANA, CURITIBA, PR, BRASIL
}

\author{
NATURAL REGENERATION OF MYRTACEAE IN AN URBAN PROTECTED AREA, \\ CURITIBA, PR, BRAZIL
}

\author{
Nathália Castanho Vieira ${ }^{1}$, Dayane May $^{2}$
}

\section{RESUMO}

Myrtaceae é uma das famílias mais representativas da Floresta Ombrófila Mista. Devido ao grande valor desta família para o ecossistema, é relevante sua regeneração natural. Deste modo, a pesquisa teve por objetivo avaliar a regeneração natural de Myrtaceae em um fragmento florestal urbano, localizado na Reserva Particular do Patrimônio Natural Municipal Airumã, Curitiba, PR. A coleta de dados foi realizada em 20 parcelas de $10 \times 10 \mathrm{~m}$ dispostas de forma aleatória, onde foram amostrados todos os indivíduos com altura de $0,5 \mathrm{~m}$ a $3 \mathrm{~m}$. Foram registrados 447 indivíduos, distribuídos em quatro gêneros e seis espécies. Myrceugenia miersiana e Myrcia hatschbachii proporcionaram os maiores valores de dominância, absoluta e relativa, em decorrência da média dos seus diâmetros. Myrciaria tenella e $M$. hatschbachii apresentaram altos valores para o índice de valor de importância pela densidade de indivíduos e frequência de distribuição. As espécies que se destacaram por estarem representadas nas duas classes de regeneração ( $M$. tenella e $M$. hatschbachii) demonstraram que sua taxa de crescimento é predominante sobre a taxa de mortalidade. A quantidade de espécies amostradas no fragmento demonstra a importância das Reservas Particulares do Patrimônio Natural Municipal na conservação da diversidade biológica.

Palavras-chave: Floresta Ombrófila Mista; Mata Atlântica; RPPNM; Ecologia urbana.

\begin{abstract}
Myrtaceae is one of the most representative families of the Mixed Ombrophilous Forest. Because of its significant natural values for environment, its natural regeneration of this family is relevant. Thus, this research aimed to survey the natural regeneration of Myrtaceae in an urban forest fragment located in the Municipal Private Reserve of Natural Heritage Airumã, Curitiba, PR, Brazil. Data were collected in 20 random $10 \times 10 \mathrm{~m}$ plots, where all individuals in a height between $0.5 \mathrm{~m}$ to $3 \mathrm{~m}$ were sampled. A total of 447 individuals were registered, distributed in four genera and six species. Due to average diameters, the species Myrceugenia miersiana and Myrcia hatschbachii presented the highest values of absolute and relative dominance, while Myrciaria tenella and Myrcia hatschbachii stood out with a high importance value index due to the frequency of distribution and density of its individuals. Species that stood out for its presence in both regeneration classes ( $M$. tenella and $M$. hatschbachii) demonstrated that its growth rate is predominant over the mortality rate. The amount of the species sampled in the fragment demonstrates the importance of the Municipal Private Reserves of Natural Heritage for conservation of biological diversity.
\end{abstract}

Keywords: Mixed Ombrophilous Forest; Atlantic Forest; RPPNM; Urban ecology.

Recebido em 11.10.2019 e aceito em 13.01.2020

1 Graduada em Ciências Biológicas-Bacharelado. Escola de Ciências e Saúde. Universidade Positivo. Curitiba/PR. Email: nathalia_vieira13@hotmail.com

2 Bióloga. Doutora. Professora do Curso de Ciências Biológicas. Escola de Ciências e Saúde. Universidade Positivo. Curitiba/PR. Email: dayane.may@up.edu.br 


\section{INTRODUÇÃO}

O bioma Mata Atlântica é composto por diversas formações florestais nativas, dentre elas a Floresta Ombrófila Mista (FOM), também denominada como Floresta com Araucária. A FOM apresenta uma elevada diversidade florística e estrutural (HIGUCHI et al., 2016). Porém, durante muitos anos, esta formação florestal sofreu com a exploração não sustentável de seus recursos (SILVA et al., 2017). Uma das famílias mais representativas da Floresta com Araucária é Myrtaceae, típica da flora nativa.

No Brasil, Myrtaceae inclui cerca de 1034 espécies e 29 gêneros, sendo que no Estado do Paraná são registrados 18 gêneros (SOBRAL et al., 2015). É uma das maiores famílias da flora brasileira, e encontra-se entre as dez mais diversas famílias de angiospermas, no bioma Mata Atlântica (FORZZA et al., 2010).

Os frutos fornecem alimento à fauna silvestre, cuja interação com os dispersores favorece a manutenção de serviços ecossistêmicos, bem como o processo de regeneração natural, caracterizando essa família com potencial para revegetação de áreas alteradas. Os principais dispersores de Myrtaceae são aves, roedores, macacos e morcegos (GOMES et al., 2017). A diminuição das áreas naturais e o aumento do grau de isolamento de populações ocasionam um impacto negativo à biodiversidade, por inviabilizar o intercâmbio entre polinizadores e dispersores de sementes.

Como a maior parte dos remanescentes de floresta com araucária está dispersa em fragmentos, as áreas protegidas urbanas, como áreas de preservação permanente, corredores ecológicos, parques e unidades de conservação, possuem um papel relevante pelos serviços ecossistêmicos que prestam como a proteção dos recursos hídricos e biodiversidade, bem como contribuem para a manutenção das populações naturais, que é dependente de sua regeneração natural. O conhecimento sobre essas características torna-se fundamental para propor ações de recuperação das populações ou estratégias de manejo.

A família Myrtaceae se destaca em estudos de levantamento florístico da regeneração natural em fragmentos da FOM, por apresentar elevado número de espécies (CHAMl et al., 2011; MEYER et al., 2013). Estes estudos permitem a inferência sobre a dinâmica de comunidades e populações de espécies arbóreas, representando uma informação fundamental para o manejo e conservação florestal (SANTOS et al., 2015).

Desta forma, a pesquisa teve como objetivo avaliar a regeneração natural de Myrtaceae em uma unidade de conservação urbana, localizada em Curitiba, Paraná. 


\section{MATERIAL E MÉTODOS}

\section{Área de estudo}

O presente estudo foi realizado na Reserva Particular do Patrimônio Natural Municipal (RPPNM) Airumã, em um fragmento de 3,6 ha de Floresta Ombrófila Mista, localizado no município de Curitiba, Paraná, nas coordenadas 2523'01,1"S e 49¹9'07,5”W (Figura 1). A RPPNM Airumã está situada no bairro de Santa Felicidade, dentro da bacia do rio Barigui e se conecta com as áreas de floresta do Parque Tingui e demais fragmentos florestais urbanos próximos (BASNIAK et al., 2015).
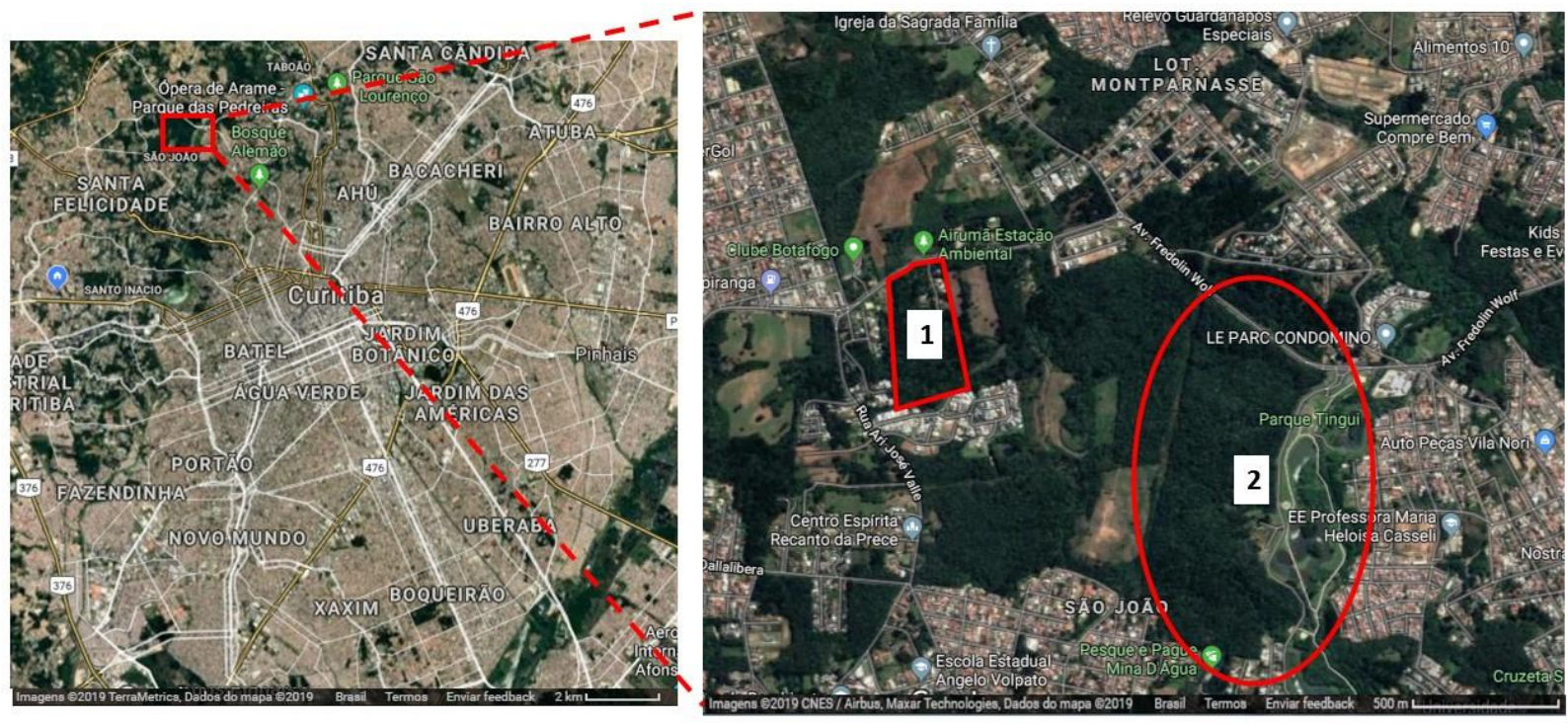

Fonte: as autoras (2019)

Figura 1. Localização da Reserva Particular do Patrimônio Natural Municipal Airumã (1) no município de Curitiba, Paraná, coordenadas $25^{\circ} 23^{\prime} 01,1^{\prime \prime}$ e e $49^{\circ} 19^{\prime} 07,5^{\prime \prime} \mathrm{W}$ e sua conectividade com as áreas verdes do Parque Tingui (2) e fragmentos florestais adjacentes.

Figure 1. Location of the Airumã Municipal Private Reserve of Natural Heritage (1) in the city of Curitiba, Paraná, coordinates $25^{\circ} 23^{\prime} 01.1$ "S and $49^{\circ} 19^{\prime} 07.5^{\prime \prime} \mathrm{W}$ and its connectivity with the green areas of Tingui Park (2) and adjacent forest fragments.

O clima do município é do tipo Cfb, segundo Köppen-Geiger, sendo temperado (ou subtropical) úmido, mesotérmico, sem estação seca, com verões frescos, invernos com geadas frequentes e ocasional precipitação de neve (INSTITUTO DE PESQUISA E PLANEJAMENTO URBANO DE CURITIBA (IPPUC), 2001).

\section{Coleta de dados}

Foram estabelecidas 20 parcelas de 10 x 10 m (MAUHS; BACKES, 2002) dentro do fragmento florestal, para identificação e mensuração dos indivíduos de Myrtaceae. Os dados foram coletados entre os meses de março e agosto de 2018. A regeneração natural foi considerada com todos os indivíduos com altura de até $3 \mathrm{~m}$ presentes nas parcelas. Além 
disso, a regeneração foi dividida em duas classes: regeneração $I$, indivíduos com altura entre 0,5 m e 1,49 m; e regeneração II, indivíduos com altura entre 1,5 m e $3 \mathrm{~m}$ (PALUDO; MANTOVANI; REIS, 2011). As medições da altura e diâmetro à altura do solo foram realizadas com o auxílio de paquímetro e trena. Para a determinação botânica, coletou-se uma amostra de cada espécie e a identificação foi realizada no Museu Botânico Municipal de Curitiba, seguindo o sistema da classificação Angiosperm Phylogeny Group IV (CHASE et al., 2016).

\section{Análise de dados}

Foram calculados parâmetros fitossociológicos de densidade (absoluta e relativa), frequência (absoluta e relativa), dominância (absoluta e relativa) e índice de valor de importância, conforme Mauhs e Backes (2002).

Para a obtenção do índice de regeneração natural, o qual indicará a porcentagem de regenerantes por espécie, de cada classe de tamanho, foi utilizada a metodologia proposta por Volpato (1994), que envolve a estimativa de densidade e frequência, absoluta e relativa, em cada classe de altura. Posteriormente, foi realizada a estimativa da regeneração natural total (RNT) por espécie, por meio da soma dos índices de regeneração natural por classe de tamanho, que equivale a 100, que mostra um índice total de regeneração das espécies de Myrtaceae na área de estudo.

\section{RESULTADOS E DISCUSSÃO}

Foram identificados 447 indivíduos, pertencentes a quatro gêneros e seis espécies de Myrtaceae. Na classe de regeneração $I$, foram encontradas as seis espécies, totalizando 371 indivíduos, com uma densidade total de 1855 ind./ha e altura média de 0,59 m (Tabela 1). As espécies registradas foram Myrciaria tenella (DC.) O. Berg (cambuí), Myrcia hatschbachii D. Legrand (caingá-verdadeiro), Myrceugenia miersiana (Gardner) D. Legrand \& Kausel (guamirim), Myrceugenia myrcioides (Cambess.) O. Berg (araçarana), Eugenia pluriflora DC. (guamirim-redondo) e Eugenia uniflora L. (pitanga). Já na classe de regeneração II, foram encontrados 76 indivíduos, pertencentes a três espécies, com densidade total de 380 ind./ha e altura média de 1,95 m (Tabela 2). Se enquadraram nesta classe: $M$. tenella, $M$. hatschbachii e M. myrcioides. Os gêneros amostrados neste fragmento também foram encontrados em outros estudos em Floresta Ombrófila Mista do Sul do Brasil (FIORENTIN et al., 2015; SANTOS et al., 2018). Dos 18 gêneros de Myrtaceae ocorrentes no Paraná, seis foram amostrados na RPPNM Airumã. (KAEHLER et al., 2014). 
Tabela 1. Relação das espécies registradas na RPPNM Airumã, classificadas na classe de regeneração le respectivos parâmetros fitossociológicos

Table 1. List of species registered in the Airumã RPPNM, classified in regeneration class I and respective phytosociological parameters

\begin{tabular}{cccccccccccc}
\hline Espécies & $\begin{array}{c}\text { Nome } \\
\text { popular }\end{array}$ & $\begin{array}{c}\mathbf{h} \\
(\mathbf{m})\end{array}$ & $\begin{array}{c}\text { DAS } \\
(\mathbf{c m})\end{array}$ & $\begin{array}{c}\text { Ni } \\
\text { Myrciaria tenella }\end{array}$ cambuí & $\begin{array}{c}\text { DA } \\
\text { (ind/ha) }\end{array}$ & $\begin{array}{c}\text { DR } \\
(\%)\end{array}$ & FA & $\begin{array}{c}\text { FR } \\
(\%)\end{array}$ & DoA & $\begin{array}{c}\text { DoR } \\
(\%)\end{array}$ & IVI \\
Myrcia hatschbachii & $\begin{array}{c}\text { caingá - } \\
\text { verdadeiro }\end{array}$ & 0,76 & 0,58 & 24 & 120 & 6,5 & 60 & 29 & 1,29 & 24 & 59 \\
Myrceugenia miersiana & guamirim & 0,73 & 0,62 & 13 & 65 & 3,5 & 15 & 7 & 1,45 & 27 & 38 \\
Myrceugenia myrcioides & araçarana & 0,59 & 0,52 & 5 & 25 & 1,3 & 25 & 12 & 1,06 & 19 & 32 \\
Eugenia pluriflora & $\begin{array}{c}\text { guamirim - } \\
\text { redondo }\end{array}$ & 0,76 & 0,30 & 1 & 5 & 0,3 & 5 & 2 & 0,35 & 6 & 9 \\
Eugenia uniflora & pitanga & 0,18 & 0,10 & 1 & 5 & 0,3 & 5 & 2 & 0,04 & 1 & 3 \\
Total & & - & - & 371 & 1855 & 100 & - & 100 & - & 100 & 300
\end{tabular}

Nota: $\mathrm{h}$ = altura média, DAS = diâmetro à altura do solo (média), $\mathrm{Ni}=$ número de indivíduos amostrados, $\mathrm{DA}=$ densidade absoluta, $\mathrm{DR}=$ densidade relativa, $\mathrm{FA}=$ frequência absoluta, $\mathrm{FR}=$ frequência relativa, $\mathrm{DoA}=$ dominância absoluta, DoR = dominância relativa, IVI = índice de valor de importância.

Tabela 2. Relação das espécies registradas na RPPNM Airumã, classificadas na classe de regeneração I/ e respectivos parâmetros fitossociológicos

Table 2. List of species registered in the Airumã RPPNM, classified in regeneration class // and respective phytosociological parameters

\begin{tabular}{cccccccccccc}
\hline Espécies & $\begin{array}{c}\text { Nome } \\
\text { popular }\end{array}$ & $\begin{array}{c}\text { h } \\
(\mathbf{m})\end{array}$ & $\begin{array}{c}\text { DAS } \\
(\mathbf{c m})\end{array}$ & $\mathbf{N i}$ & $\begin{array}{c}\text { DA } \\
\text { (ind/ha) }\end{array}$ & $\begin{array}{c}\text { DR } \\
(\%)\end{array}$ & FA & $\begin{array}{c}\text { FR } \\
(\%)\end{array}$ & DoA & $\begin{array}{c}\text { DoR } \\
(\%)\end{array}$ & IVI \\
\hline Myrciaria tenella & cambuí & 2,03 & 1,91 & 59 & 295 & 77,6 & 75 & 71 & 14,3 & 44 & 193 \\
Myrcia hatschbachii & $\begin{array}{c}\text { caingá - } \\
\text { verdadeiro }\end{array}$ & 2,17 & 2,02 & 16 & 80 & 21,1 & 25 & 24 & 16,0 & 49 & 94 \\
Myrceugenia myrcioides & araçarana & 1,66 & 0,80 & 1 & 5 & 1,3 & 5 & 5 & 2,5 & 7 & 13 \\
Total & & - & - & 76 & 380 & 100 & - & 100 & - & 100 & 300 \\
\hline
\end{tabular}

Nota: $\mathrm{h}=$ altura média, DAS = diâmetro a altura do solo (média), $\mathrm{Ni}=$ número de indivíduos amostrados, $\mathrm{DA}=$ densidade absoluta, $\mathrm{DR}=$ densidade relativa, $\mathrm{FA}=$ frequência absoluta, $\mathrm{FR}=$ frequência relativa, $\mathrm{DoA}=$ dominância absoluta, DoR = dominância relativa, IVI = índice de valor de importância.

A espécie que apresentou o maior número de indivíduos amostrados nas duas classes de regeneração foi $M$. tenella com um total de 386 indivíduos. Esta espécie também apresentou o maior valor de importância em ambas as classes de regeneração e $M$. hatschbachii resultou no segundo maior valor de importância na classe de regeneração I, assim como na regeneração II (Tabelas 1 e 2).

Além disso, M. tenella exibiu os maiores valores de densidade absoluta (DA), demonstrando que apresenta 1635 indivíduos por hectare (ind/ha) e densidade relativa (DR), com um valor de $88,1 \%$, em relação com as outras espécies amostradas. Seus altos valores de frequência absoluta $(F A=100)$ e frequência relativa $(F R=48 \%)$ na regeneração $/$ indicam que 
os indivíduos dessa espécie se encontram distribuídos em todas as parcelas amostradas (MAUHS; BAKES, 2002). O mesmo ocorre na regeneração II, com os maiores valores de densidade absoluta (295), densidade relativa (77,6\%), frequência absoluta (75) e frequência relativa (71\%).

O maior valor de dominância absoluta ( $\mathrm{DoA}=1,45$ ) e dominância relativa ( $\mathrm{DoR}=27 \%$ ), na classe de regeneração / foi de $M$. miersiana. Na regeneração II, $M$. hatschbachii se destacou com um valor de 16 em dominância absoluta e 49\% em dominância relativa. Estes valores se deram em decorrência da média do diâmetro a altura do solo (DAS) que as duas apresentaram, sendo superiores às outras espécies, o que ocasionou em um aumento do parâmetro de dominância das mesmas. De acordo com Watzlawick et al. (2005), M. tenella e M. hatschbachii se destacaram com altos valores para o índice de valor de importância (IVI) pela densidade de indivíduos e pela frequência de distribuição dos mesmos.

M. tenella, popularmente conhecida como cambuí, é uma espécie frutífera, pioneira, esciófita ou heliófita, que se torna abundante em terrenos úmidos (LEGRAND; KLEIN, 1978). É muito citada em trabalhos de regeneração natural em Floresta Ombrófila Mista, pois a floresta apresenta características favoráveis, como sombra e umidade, para seu desenvolvimento (GASPER et al., 2013).

A classe de regeneração I exibiu o maior número de indivíduos por parcela. Em todas as parcelas desta classe foram registrados exemplares que variaram de quatro a 44 indivíduos (Figura 1). Em contrapartida, a classe de regeneração // apresentou poucos indivíduos. Em três, das 20 parcelas, nenhum exemplar com altura acima de $1,5 \mathrm{~m}$ foi registrado. Além disso, 0 maior número de indivíduos encontrados (11) foi consideravelmente baixo, quando comparado à classe de regeneração I (Figura 2).

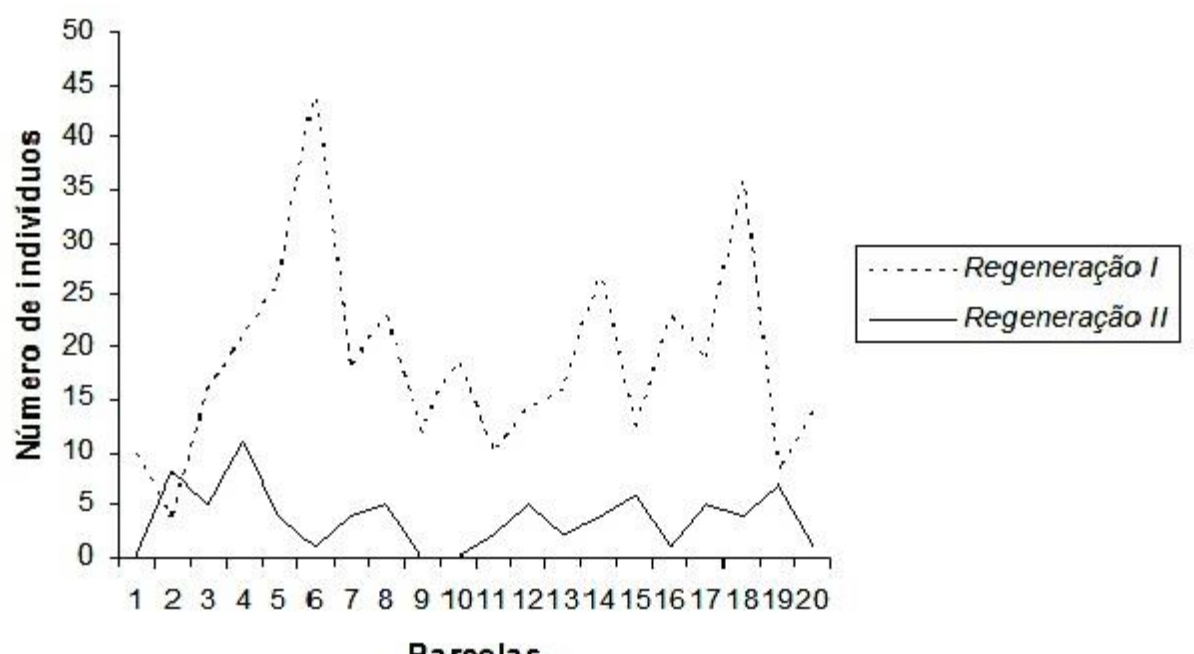

Figura 2. Relação da quantidade de indivíduos amostrados por parcela, considerando as classes de regeneração I e II 
Figure 2. Relation of the number of individuals sampled per plot, considering regeneration classes I and II

Esta baixa quantidade de regenerantes componentes da classe de regeneração II pode ter ocorrido por motivos distintos, como a presença de determinada limitação ecológica para o desenvolvimento (por fatores ambientais ou bióticos) ou, até mesmo pela possibilidade de serem espécies secundárias tardias, ou seja, de crescimento lento ou moderado, tolerantes à sombra durante muitos anos da vida. As que não foram registradas nesta classe podem ter sofrido competição, predação ou influência da luminosidade e temperatura (SANTOS et al., 2018). As espécies que ocorrem nas duas classes de regeneração natural são aquelas que, teoricamente, possuem um maior potencial de estabelecimento na floresta e que deverão estar presentes futuramente no dossel (SILVA et al., 2007).

As espécies que apresentaram maiores índices de regeneração natural total dentro das classes de altura (RNT) foram M. tenella (71,20\%) e M. hatschbachii $(20,10 \%)$ (Tabela 3). Estas espécies juntas representaram $91,30 \%$ da RNT dentro das classes de altura. A regeneração natural na classe de regeneração I também demonstrou maiores percentuais para M. tenella $(68,50 \%)$ e M. hatschbachii $(17,75 \%)$, sendo que $E$. pluriflora $(1,15 \%)$ e $E$. uniflora $(1,15 \%)$ apresentaram os menores valores (Tabela 3$)$. A regeneração natural na classe de regeneração I/ manifestou valores apenas para três espécies, pois $M$. miersiana, E. pluriflora e E. uniflora não foram encontradas nesta classe. M. tenella obteve o maior valor $(74,3 \%)$, seguida por M. hatschbachii (22,55\%) e M. myrcioides (3,15\%) (Tabela 3).

Tabela 3. Estimativa da Regeneração Natural Total dentro das classes de altura (RNT) por espécie, bem como a estimativa da regeneração natural por classe de altura

Table 3. Estimation of Total Natural Regeneration within the height classes (RNT) by species, as well as the estimate of natural regeneration by height class

\begin{tabular}{ccccc}
\hline Espécies & Nome popular & RNC1 (\%) & RNC2 (\%) $^{2}$ & RNT (\%) \\
\hline Myrciaria tenella & cambuí & 68,50 & 74,30 & 71,20 \\
$\begin{array}{c}\text { Myrcia } \\
\text { hatschbachii }\end{array}$ & $\begin{array}{c}\text { caingá - } \\
\text { verdadeiro }\end{array}$ & 17,75 & 22,55 & 20,10 \\
$\begin{array}{c}\text { Myrceugenia } \\
\text { miersiana }\end{array}$ & guamirim & 5,25 & 0 & 2,64 \\
$\begin{array}{c}\text { Myrceugenia } \\
\text { myrcioides }\end{array}$ & araçarana & 6,65 & 3,15 & 4,90 \\
$\begin{array}{c}\text { Eugenia } \\
\text { pluriflora }\end{array}$ & $\begin{array}{c}\text { guamirim - } \\
\text { redondo }\end{array}$ & 1,15 & 0 & 0,58 \\
$\begin{array}{c}\text { Eugenia uniflora } \\
\text { Total }\end{array}$ & pitanga & 1,15 & 0 & 0,58 \\
\hline
\end{tabular}


Nota: $\mathrm{RNC}^{1}=$ Regeneração Natural da Classe de regeneração I; $\mathrm{RNC}^{2}=$ Regeneração Natural da Classe de regeneração II.

E. pluriflora e E. uniflora, por terem apresentados valores de RNT inferiores a $1 \%$, demonstram que, a partir de determinado tempo, podem passar a ter um alto grau de dificuldade em se regenerar. Além disso, Martinazzo et al. (2007) ressaltam que o crescimento inicial de E. uniflora é favorecido por alta luminosidade, o que não ocorre neste fragmento. As espécies que se destacaram por estarem bem representadas nas duas classes de regeneração (M. tenella e $M$. hatschbachii) possivelmente obtiveram estes valores devido a sua taxa de crescimento ser predominante sobre a taxa de mortalidade (SILVA et al., 2007).

Todas as espécies amostradas são nativas do Brasil, sendo $M$. miersiana, $M$. myrcioides e E. pluriflora endêmicas do país e, M. hatschbachii, endêmica do Estado do Paraná (Tabela 4). Além disso, M. hatschbachii é considerada Vulnerável (VU) pelo Livro Vermelho da Flora do Brasil (MARTINELLI; MORAES, 2013), demonstrando a importância das Reservas Particulares do Patrimônio Natural Municipal na proteção de espécies endêmicas e na conservação de espécies e ecossistemas (BASNIAK et al., 2015).

Tabela 4. Espécies amostradas na RPPNM Airumã, bem como sua ocorrência, endemismo e status de conservação

Table 4. Species sampled in the Airumã RPPNM, as well as its occurrence, endemism and conservation status

\begin{tabular}{|c|c|c|c|c|c|}
\hline Espécies & Nome popular & Nativa & $\begin{array}{l}\text { Endêmica } \\
\text { do Brasil }\end{array}$ & $\begin{array}{l}\text { Endêmica } \\
\text { do Paraná }\end{array}$ & $\begin{array}{c}\text { Status de } \\
\text { conservação }\end{array}$ \\
\hline Myrciaria tenella & cambuí & Sim & Não & Não & DD \\
\hline Myrcia hatschbachii & $\begin{array}{c}\text { caingá - } \\
\text { verdadeiro }\end{array}$ & Sim & Não & Sim & VU \\
\hline Myrceugenia miersiana & guamirim & Sim & Sim & Não & LC \\
\hline Myrceugenia myrcioides & araçarana & Sim & Sim & Não & LC \\
\hline Eugenia pluriflora & $\begin{array}{l}\text { guamirim - } \\
\text { redondo }\end{array}$ & Sim & Sim & Não & LC \\
\hline Eugenia uniflora & pitanga & Sim & Não & Não & - \\
\hline
\end{tabular}

Os fragmentos florestais urbanos contribuem para diversos aspectos ambientais, como: equilíbrio climático, qualidade do ar, controle de erosão, além da preservação da flora e fauna (BASNIAK et al., 2015). A Reserva Particular do Patrimônio Natural (RPPN) é uma área privada, gravada com perpetuidade, com o objetivo de conservar a diversidade biológica, na qual só é permitida a pesquisa científica e a visitação com objetivos turísticos, recreativos e educacionais (BRASIL, 2000). São instituídas segundo o artigo 21, da Lei do Sistema Nacional de Unidades de 
Conservação - SNUC (BRASIL, 2000) e a criação de áreas protegidas favorece a formação de corredores ecológicos, aumentando a variabilidade genética, por meio da dispersão de sementes, que ocorre entre as áreas conectadas.

\section{CONCLUSÕES}

É possível afirmar que espécies de Myrtaceae apresentam potencial de regeneração natural em Floresta Ombrófila Mista, com ênfase para Myrciaria tenella que se destacou com o maior número de indivíduos tanto na classe de regeneração I, quanto na regeneração II.

A partir da análise fitossociológica, foi possível demonstrar a importância da RPPNM Airumã para a conservação de espécies nativas, uma vez que, dos 18 gêneros de Myrtaceae ocorrentes no Paraná, 33,4\% foi amostrado nesse fragmento.

Sugere-se a realização de um monitoramento em longo prazo da regeneração natural neste fragmento florestal urbano, com a finalidade de dar continuidade à pesquisa, uma vez que esta área verde apresenta conectividade com o Parque Tingui, forma corredores ecológicos, favorece a dispersão de sementes e, consequentemente a variabilidade genética, o que torna sua conservação relevante.

\section{AGRADECIMENTOS}

Agradecemos à Teresinha Vareschi, proprietária da RPPNM Airumã por permitir a realização do estudo no local. Agradecemos também ao Museu Botânico Municipal de Curitiba pelo auxílio na identificação das espécies.

\section{REFERÊNCIAS}

BASNIAK, T. R.; SOARES, R. V.; TETTO, A. F.; MEIRA, M. Efetividade de manejo de Reservas Particulares do Patrimônio Natural Municipais: o caso da RPPNM Airumã, Curitiba/PR. Enciclopédia Biosfera, Goiânia, v. 11, n. 22, p. 1107-1119, 2015.

BRASIL. Lei no 9.985, de 18 de julho de 2000. Institui o Sistema Nacional de Unidades de Conservação da Natureza e dá outras providências. Diário Oficial [da] República Federativa do Brasil, Brasília, DF, 18 jul. 2000. Disponível em: <http://www.planalto.gov.br/ccivil_03/Leis/L9985.htm>. Acesso em: 12 set. 2018.

CHAMI, L. B.; ARAUJO, M. M.; LONGHI, S. J.; KIELSE, P.; LÚCIO, A. D. Mecanismos de regeneração natural em diferentes ambientes de remanescente de Floresta Ombrófila Mista, São Francisco de Paula, RS. Ciência Rural, Santa Maria v. 41, n. 02, p. 251-259, 2011. 
CHASE, M. W.; CHRISTENHUSZ. M. J. M.; FAY, M. F.; BYNG, J. W.; JUDD, W. S.; SOLTIS, D. E.; MABBERLEY, D. J.; SENNIKOV, A. N.; SOLTIS, P. S.; STEVENS, P. F. An update of the Angiosperm Phylogeny Group classification for the orders and families of flowering plants: APG IV. Botanical Journal of the Linnean Society, Londres, v. 181, n. 1, p. 1-20, 2016.

FIORENTIN, L. D.; TÉO, S. J.; SCHNEIDER, C. R.; COSTA, R. H.; BATISTA, S. Análise florística e padrão espacial da regeneração natural em área de Floresta Ombrófila Mista na região de Caçador, SC. Floresta e Ambiente, Seropédica, v. 22, n. 1, p. 60-70, 2015.

FORZZA, R. C.; BAUMGRATZ, J. F. A.; BICUDO, C. E. M.; CARVALHO JÚNIOR, A. A.; COSTA, A.; COSTA, D. P.; HOPKINS, M.; LEITMAN, P. M.; LOHMANN, L. G.; MAIA, L. C.; MARTINELLI, G.; MENEZES, M.; MORIM, M. P.; COELHO, M. A. N.; PEIXOTO, A. L.; PIRANI, J. R.; PRADO, J.; QUEIROZ, L. P.; SOUZA, V. C.; STEHMANN, J. R.; SYLVESTRE, L. S.; WALTER, B. M. T.; ZAPPI, D. Catálogo de plantas e fungos do Brasil. Rio de Janeiro: Andrea Jakobsson Estúdio, 2010. 871p.

GASPER, A. L.; SEVEGNANI, L.; VIBRANS, A. C.; SOBRAL, M.; UHLMANN, A.; LINGNER, D. V.; RIGON-JÚNIOR, M. J.; VERDI, M.; STIVAL-SANTOS, A.; DREVECK, S.; KORTE, A. Inventário florístico florestal de Santa Catarina: espécies da Floresta Ombrófila Mista. Rodriguésia, Rio de Janeiro, v. 64, n. 2, p. 201-210, 2013.

GOMES, J. P.; DACOREGIO, H. M.; SILVA, K. M.; ROSA, L. H.; BORTOLUZZI, R. L. C. Myrtaceae na Bacia do rio Caveiras: Características ecológicas e usos não madeireiros. Floresta e Ambiente, Seropédica, v. 24, p. 1-10, 2017.

HIGUCHI, P.; SILVA, A. C.; FERREIRA, T. S.; SOUZA, S. T.; GOMES, J. P.; SILVA, K. M.; SANTOS, K. F.; BERNDT, E. J.; JUNIOR, J. O. S.; GOIS, D. T.; WEIDUSCHAT, F. Florística e estrutura do componente arbóreo e relação com variáveis ambientais em um remanescente florestal em Campos Covos - SC. Ciência Florestal, Santa Maria, v. 26, n. 1, p. 35-46, 2016.

INSTITUTO DE PESQUISA E PLANEJAMENTO URBANO DE CURITIBA (IPPUC). Curitiba em Dados. 2001. Disponível em: <http://curitibaemdados.ippuc.org.br> Acesso em: 06 jun. 2019.

KAEHLER, M.; GOLDENBERG, R.; LABIAK, P. H.; RIBAS, O. S.; VIEIRA, A. O. S.; HATSCHBACH, G. G. Plantas vasculares do Paraná. Curitiba: Departamento de Botânica, 2014. 181p.

LEGRAND, C. D.; KLEIN, R. M. Mirtáceas. 17. Myrciaria, 18. Pseudocaryophyllus, 19. Blepharocalyx, 20. Espécies suplementares, 21. Espécies cultivadas, 22. Generalidades: chave dos gêneros. Literatura. Conspecto geral das Mirtáceas. Índice. In: Reitz, R. (ed.). Flora Ilustrada Catarinense. Itajaí: Herbário Barbosa Rodrigues, 1978.

MARTINAZZO, E. G.; ANESE, S.; WANDSCHEER, D.; PASTORINI, L. H. Efeito do sombreamento sobre o crescimento inicial e teor de clorofila folias de Eugenia uniflora Linn (pitanga) - Família Myrtaceae. Revista Brasileira de Biociências, Porto Alegre, v. 5, n. 2, p. 162-164, 2007.

MARTINELLI, G.; MORAES, M. A. Livro vermelho da flora do Brasil. Rio de Janeiro: Instituto de Pesquisas Jardim Botânico do Rio de Janeiro, 2013. 1100p. 
MAUHS, J.; BACKES, A. Estrutura fitossociológica e regeneração natural de um fragmento de Floresta Ombrófila Mista exposto a perturbações antrópicas. Pesquisas, Série Botânica, São Leopoldo, v. 52, p. 89-109, 2002.

MEYER, L.; GASPER, A. L.; SEVEGNANI, L.; SCHORN, L. A.; VIBRANS, A. C.; LINGNER, D. V.; VERDI, M.; SANTOS, A. S.; DREVECK, S.; KORTE, A. Regeneração natural na Floresta Ombrófila Mista em Santa Catarina. In: Vibrans AC, Sevegani L, Gasper AL de, Lingner DV. (Eds) Volume III - Inventário Florístico Florestal de Santa Catarina. Floresta Ombrófila Mista. Edifurb, Blumenau, 191-222, 2013.

PALUDO, G. F.; MANTOVANI, A.; REIS, M. S. Regeneração de uma população natural de Araucaria angustifolia (Araucariaceae). Árvore, Viçosa, v. 35, n. 5, p. 1107-1119, 2011.

SANTOS, K. F.; FERREIRA, T. S.; HIGUCHI, P.; SILVA, A. C.; VANDRESEN, P. B.; COSTA, A.; SPADA, G.; SCHMITZ, V.; SOUZA, F. Regeneração natural do componente arbóreo após a mortalidade de um maciço de taquara em um fragmento de Floresta Ombrófila Mista em Lages - SC. Ciência Florestal, v. 25, n.1, p. 107-117, 2015.

SANTOS, G. N.; HIGUCHI, P.; SILVA, A. C.; FARIAS, K. J.; MACHADO, F. D.; DUARTE, E.; FERNANDES, C.; VIEIRA, F.; AMARAL, R. S.; AGUIAR, V.; WALTER, F. F.; MORES, B.; REIS, M. A. Regeneração natural em uma floresta com araucária: inferências sobre o processo de construção da comunidade de espécies arbóreas. Ciência Florestal, Santa Maria, v. 28, n. 2, p. 483-494, 2018.

SILVA, W. C.; MARANGON, L. C.; FERREIRA, R. L. C.; FELICIANO, A. L. P.; JUNIOR, R. F. C. Estudo da regeneração natural de espécies arbóreas em fragmento de Floresta Ombrófila Densa, Mata das Galinhas, no município de Catende, zona da Mata Sul de Pernambuco. Ciência Florestal, Santa Maria, v. 17, n. 4, p. 321-331, 2007.

SILVA, M. T. S.; OLIVEIRA, G. S.; DREYER, J. B. B.; SCHLICKMANN, M. B.; DREYER, T. C.; ATANAZIO, K. A. Parâmetros fitossociológicos de um fragmento de Floresta Ombrófila Mista em regeneração após queimada no município de Segredo, RS. Scientia Agraria Paranaensis, Marechal Cândido Rondon, v. 16, n. 3, p. 408-413, 2017.

SOBRAL, M.; PROENÇA, C.; SOUZA, M.; MAZINE, F.; LUCAS, E. 2015 Myrtaceae in Lista de Espécies da Flora do Brasil. 2015. Disponível em: <http://floradobrasil.jbrj.gov.br/jabot/floradobrasil/FB171> Acesso em: 08 dez. 2019.

VOLPATO, M. M. L. Regeneração natural em uma floresta secundária no domínio de Mata Atlântica: uma análise fitossociológica. 123f. Dissertação (Mestrado em Engenharia Florestal) - Universidade Federal de Viçosa, Viçosa, 1994.

WATZLAWICK, L. F.; SANQUETTA, C. R.; VALÉRIO, A. F.; SILVESTRE, R. Caracterização da composição florística e estrutura de uma Floresta Ombrófila Mista, no município de General Carneiro (PR). Ambiência, Guarapuava, v. 1, n. 2, p. 229-237, 2005. 